\section{Renée Ferrer}

Poeta, narradora y ensayista paraguaya, nacida en 1944. Doctorada en Historia por la Universidad Nacional de Asunción, Renée Ferrer es una de las escritoras más prolíficas de su generación. De sus obras publicadas, cabe destacar, en poesía: Hay surcos que no se llenan (1965), Voces sin réplica (1967), Desde el cañadón de la memoria (1984), Peregrino de la eternidad (1985), Sobreviviente (1985), Nocturnos (1987), Viaje a destiempo (1989), De lugares, momentos e implicancias varias (1990) y El acantilado y el mar (1992). En el cuento, ha editado La Seca y otros cuentos (1986), Por el ojo de la cerradura (1993) y Desde el encendido corazón del monte (1994), de tema ecológico. También es autora de poemarios y cuentos infantiles. Ha publicado dos novelas: Los nudos del silencio (1988) y Vagos sin tierra (1999). Ha adaptado al teatro los cuentos «La sequía» de Rodrigo Díaz-Pérez, y «Hay que matar un chancho» y «La colección de relojes», de su propia autoría. Como crítica, ha publicado su trabajo Literatura paraguaya: dos vertientes.
La liberación de la mujer a través de la escritura

\title{
LA LIBERACIÓN DE LA MUJER A TRAVÉS DE LA ESCRITURA
}

RENÉE FERRER

Poco se sabe en el exterior de la narrativa paraguaya actual, exceptuando los textos elaborados fuera del país por escritores varones víctimas del exilio, voluntario o forzoso, el cual, si bien les marcó un azaroso destino de desdicha, contribuyó al contacto con los polos de cultura, y al acceso a las editoriales extranjeras que garantizaron la difusión de sus obras. Nadie ignora los nombres y la excelencia de la producción literaria de Augusto Roa Bastos, Gabriel Casaccia, Elvio Romero o Rubén Bareiro Saguier, pero es menos frecuente que se conozcan los de aquellos creadores, sean hombres o mujeres, que escribieron o escriben aislados dentro del territorio nacional.

Este trabajo intenta demostrar, a la luz de la bibliografía actual, la presencia de la mujer en la narrativa paraguaya, y la manera en que la expresión literaria ha servido de factor liberador.

El aislamiento provocado por las lamentables circunstancias políticas, así como las condiciones geográficas de mediterraneidad, nos condenaron al desconocimiento en el exterior de cuanto se escribió dentro de este espacio que se ha dado en llamar el «pozo cultural», al decir del poeta Carlos Villagra Marsal, o una «isla rodeada de tierra», como acertadamente lo definió Augusto Roa Bastos. En estas expresiones, tan drásticas como penetrantes, está definido nuestro destino de nación condenada a una supervivencia solitaria a espaldas del desenvolvimiento cultural del planeta, $y$, en el mejor de los casos, a contracorriente de las «escuelas literarias» o técnicas narrativas en uso, hecho que conllevó durante mucho tiempo la marca nefasta de la desactualización.
Agudiza esta marginalidad de la prosa de ficción, el peculiar interés de nuestros intelectuales de comienzos de siglo por la reelaboración histórica y la defensa de nuestros derechos sobre la región occidental, tema obligado en el momento de los conflictos territoriales que desembocaron en la Guerra del Chaco.

No obstante las condiciones adversas, la narrativa paraguaya se abrió paso por ese arduo sendero del aislamiento, y son las mujeres con vocación literaria quienes están proponiendo un nuevo ángulo de mira en los últimos años. Las primeras manifestaciones narrativas de acento femenino se centran en los temas costumbristas siguiendo las pautas del relato. En esa línea se encuentran las obras de la neo-romántica Teresa Lamas Caríssimo (1897-1975), quien publica en 1921 Tradiciones del hogar, a la cual le sigue una segunda serie en 1928, más tarde Huerta de odios (1944) y La casa y la sombra (1955), siempre dentro del corte tradicional de la época. Tenemos que esperar la aparición de otra neorromántica, Concepción Leyes de Chaves (1889-1985), quien publica en 1941 su novela Tava-i, tributaria a la vertiente del folklore, para encontrar el punto de partida de la novelística femenina del siglo XX en el Paraguay. Esta autora, que se mantuvo dentro de la línea habitual del costumbrismo y las leyendas en sus libro Río Lunado, mitos y costumbres del $\mathrm{Pa}$ raguay (Bs.As. 1951), se adentra en la novelística siguiendo al inicio la corriente temática y estética del momento, para abordar posteriormente el tema histórico con una biografía novelada Madama Linch (1957). La historia ha 
sido en el Paraguay una cantera de mayúscula frecuentación, a la cual las mujeres no se mostraron indiferentes.

Debemos aguardar a la década de los años sesenta para que la polifacética Josefina Plá (1902-1999), nacida en Islas Canarias, conocida ya como poetisa y ceramista, haga su aparición como narradora con la selección de cuentos La mano en la tierra (1963), inaugurando una óptica cuestionadora, que se adscribe a un realismo crítico, totalmente diferente al costumbrismo en boga. Dos décadas después, el movimiento editorial de los años 80 , aparecido como una suerte de resistencia a la dictadura, y a pesar de ella, rectifica el largo silencio que pesa sobre las obras de ficción de Josefina, dando a conocer El espejo y el canasto (1981), La pierna de Severina (1983) y La muralla robada (1989), colecciones de cuentos que incluyen textos muy anteriores a la fecha de su publicación, donde se encuentra una aguda crítica social. Josefina Plá escribió además, en colaboración con Ángel Pérez Pardella, la novela Alguien muere en San Onofre de Guarumi (1984) plasmando la realidad urbana y rural de su país adoptivo, así como obras de teatro, ensayos, crítica literaria y cuentos infantiles, tal como lo hicieron $\mathrm{Ma}$ ría Luisa Artecona de Thompson (1923), Nidia Sanabria de Romero (1928), Teresita Torcida y otras, pioneras de la literatura infantil en el Paraguay.

Por la misma época se da a conocer Ana Iris Chaves de Ferreiro con la novela Crónica de una familia (1966), donde reconstruye la vida de un grupo familiar a lo largo de varias generaciones, siguiendo el patrón de las sagas europeas. A esta obra le sigue Andresa Escobar (1975) y varias colecciones de cuentos, tales como Fábulas modernas (1983), Retrato de nuestro amor (1984) y Crisantemos color naranja (1989), donde despliega cierto tremendismo e introduce a la mujer como personaje crítico e irónico frente al sexo opuesto y a la sociedad que la sojuzga.

La conocida poetisa Ester de Izaguirre (1924), residente en la Argentina, se revela, en 1973, como una narradora de extraordinaria economía verbal, poderosa fuerza expresiva y un manejo excelente del desenlace imprevisto, con el libro de cuentos Yo soy el tiempo, (Buenos Aires, 1973), publicado en Buenos Aires. A esta serie le sigue Último domicilio conocido (1990), obra que viene a engrosar el boom de la literatura femenina en el Paraguay, del cual hablaremos posteriormente. Existe en la palabra de Ester de Izaguirre un temblor sugerente $y$ una hondura pocas veces alcanzada con trazos tan escuetos, pero sobre todo se percibe en ella esa certera penetración sobre la situación de la mujer.

No obstante las muestras de estas escritoras al inicio de la segunda mitad del siglo XX, la narrativa de cuño femenino se desarrolla con mayor vigor a partir de 1980, cuando empieza a advertirse una toma de conciencia de género como rasgo liberador, además de una mayor pluralidad temática, así como notables variacio-

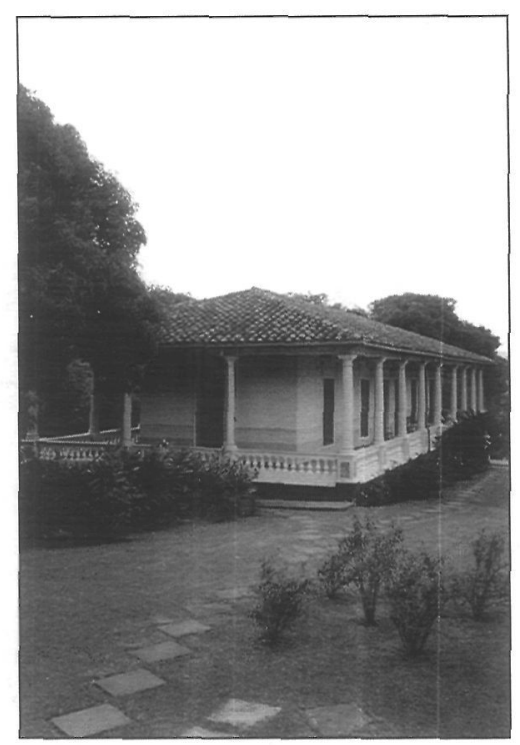

Casa colonial, Areguá. (Foto: Mar Langa). nes estilísticas.

Si las narradoras de principios de siglo se limitaron a escribir dentro de un esquema tradicional, sin apartarse por lo general del costumbrismo o del realismo de la vida rural o urbana; si la escritura de las que les sucedieron constituyó una tímida denuncia de esa sociedad patriarcal y castradora a la cual la mujer se vio sometida desde tiempo inmemorial, es en los últimos veinte años donde podemos encontrar la expresión liberadora de la mujer, dispuesta a contarse a sí misma desde una óptica netamente femenina, ignorando los esquemas que la educación tradicional y el imperio del hombre le han impuesto. Varias son las vías utilizadas por la mujer escritora para conseguir esa liberación a través de la escritura. Las mismas van desde la introspección con el concomitante enfrentamiento consigo misma, hasta el planteamiento de la infidelidad como un derecho a la felicidad; desde el lesbianismo como respuesta psicológica a la explotación sexual masculina a la alienación, la autoeliminación, el crimen o la locura, sin que falten los casos de un franco erotismo o de una rebelión abierta y sin rodeos.

En la década de los ochenta la narrativa paraguaya escrita dentro del país experimenta, en general, una eclosión inusitada. Por un lado autores nuevos o postergados por las dificultades editoriales publican sus obras, amparados en el empuje que la Editorial NAPA dio a los escritores nacionales, por otro la aparición de voces femeninas se manifiesta con gran fuerza y continuidad. Es desde esta década en adelante que se empieza a notar esa
La liberación de la mujer a través de la escritura RENEE FERRER 


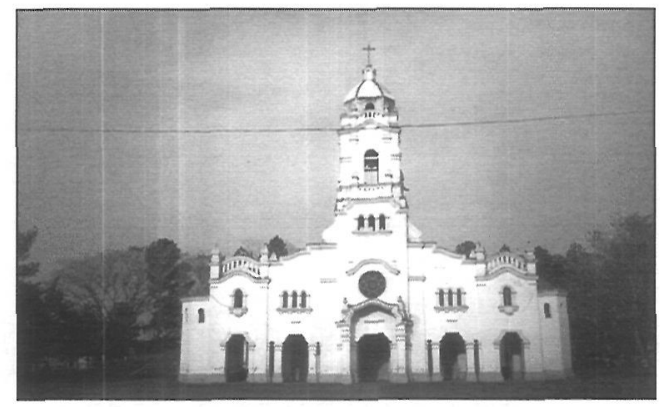

Iglesia. (Foto: Mar Langa). determinación de la mujer en revelarse, y a su vez rebelarse, a través de su propio discurso, sin olvidar que ya anteriormente algunos textos de Josefina Plá pueden considerarse paradigmáticos de esta actitud de reivindicación de la mujer por medio de la palabra escrita.

La primera en abrir el fuego, dentro de lo que podría llamarse «el boom» de la narrativa escrita por la mujer en el Paraguay, es Neida de Mendonça (1933), con Golpe de luz (1983), novela de introspección femenina en busca de la auténtica libertad. El viaje hacia el fondo de sí misma y el descubrimiento de la propia interioridad constituyen el argumento de esta novela perteneciente al género confesional, la cual significó en el momento de su publicación un desafío a la sociedad y una prueba de coraje de la autora frente al espíritu estrecho de la época. Estructurada sobre una base autobiográfi$c a$, entra sin embargo en el terreno de la ficción mediante el delineamiento de un personaje femenino que después de un intento de suicidio, a través de las sesiones con el psicoanalista, va descubriendo su identidad y conquistando el derecho a ser tal cual es, sin sometimientos ni censuras.

Neida publica posteriormente tres colecciones de cuentos Hacia el confín (1986), De polvo y de viento (1988) y Ora pro nobis (1993), donde con lenguaje poético y sugerente, manifiesta su constante preocupación por la situación de la mujer y la búsqueda de una liberación que la redima de su situación de dependencia física y moral. La rebeldía manifiesta por la autora de Golpe de Luz llega a su máxima expresión en el cuento, escrito en forma epistolar, "Que la muerte nos separe» (De polvo y de viento), donde la protagonista defiende su libertad después de la muerte, ya que no pudo ejercerla en la vida.

Raquel Saguier (1940) se abrió camino en la literatura paraguaya con la publicación de La niña que perdí en el circo (1987), una deliciosa novela de iniciación, donde la autora recobra de la mano de la poesía el perdido territorio de la infancia. Si en La niña que perdi en el circo se vislumbra ya una cierta denuncia a la situación opresiva a la cual se ajusta la vida de una mujer burguesa en una sociedad dominada por el ethos masculino, es en La vera bistoria de Purificación (1989) y en su siguiente novela Esta zanja está ocupada (1994), donde Raquel Saguier se pronuncia abiertamente contra la desigualdad de los patrones de conducta del hombre y de la mujer. La novela $\mathrm{La}$ posta del placer (1999) completa la obra de esta excelente novelista de prosa lujosa y acabado manejo de la ironía, donde se exterioriza con mayor fuerza la liberación de la doble moral de sociedades tradicionales como la nuestra. El peso resultante de la incomunicación, la soledad y el absurdo son otros elementos que juegan en la trama, donde el protagonista es un prisionero de sí mismo. Nada mejor para dar testimonio de la acción liberadora de la palabra que citar la obra de Raquel Saguier, quien nos describe en La vera historia de Purificación «el duro oficio de ser mujer en una sociedad patriarcal, inficionada de hipocresía y autoritarismos».

Así como las protagonistas de otras autoras se escapan de la opresión por medio de la alienación o la muerte, Saguier opta por la infidelidad de la protagonista como manifestación de rebeldía. En La vera bistoria de Purificación una mujer madura y ejemplar se rebela contra una vida de renunciamientos y abnegación, manteniendo una relación clandestina que es juzgada por un tribunal imaginario. La voz de la sociedad se deja escuchar con un rigor implacable, dando testimonio de la censura que coarta la vida de la mujer.

La literatura de voz femenina tiene desde los inicios de la década de los ochenta ese tinte de rebelión y cuestionamiento que la convierten en una denuncia social a través de la estética, de la cual Saguier hace gala en su tercera novela Esta zanja está ocupada (1994), donde pormenoriza con agudeza y sentido del humor la corrupción imperante en el país, siguiendo una trama de corte policial sazonada por el indispensable ingrediente de suspenso. «La rebeldía de Raquel Saguier se ajusta a un tono más social que el de sus anteriores obras y se enfrenta directamente con la mentalidad de la sociedad paraguaya dominada por los hombres», nos dice José Vicente Peiró en relación con esta obra. Asimismo se encuentra en Raquel Saguier la utilización de la ironía como arma eficaz de «combatir un mundo desigualitario en hombres y mujeres», lo cual confiere a la obra una incisiva penetración psi- a liberación de la mujer RENÉE FERRER 
cológica y propone una manera de defenderse del dominio masculino.

Sara Karlik (1935) es otra narradora y dramaturga, residente en Chile, que cultiva la ficción breve y la novela con especial cuidado y abundante producción. Se da a conocer con la colección de cuentos La oscuridad de afuera (Santiago, 1987), afianzando su entrada en la narrativa con títulos tales como Entre ánimas y sueños (1987), Demasiada historia (1988), Efectos especiales (1989), Preludio con fuga (1992) y Presentes anteriores (1996). Tiene publicada la obra teatral No bay refugio para todos, y varias novelas inéditas, tales como Los fantasmas no son como antes; Juicio de la memoria, La mesa larga (1994) y El lado absurdo de la razón. Por la manera de expresar la realidad interna de sus personajes pertenece a una corriente psicologista, ingresando «en la nueva narrativa del subconciente por caminos sesgados pero precisos», con una prosa donde se observa «la continua irrupción de la función poética en el discurso-obsesión narrativo». La múltiple bibliografía de Karlik se vio enriquecida con su última novela Nocturno para errantes eternos (1999), donde retorna al mundo de su infancia, relatando las peripecias del grupo de inmigrantes judíos establecidos en el Paraguay en las primeras décadas de este siglo.

Por la misma fecha de aparición de La niña que perdí en el circo, de Raquel Saguier, Lucy Mendonça de Spinzi (1932) publica Tierra mansa y otros cuentos (1987). Ceramista, periodista, autora teatral y narradora de gran fuerza expresiva, Lucy Mendonça utiliza con suma habilidad el castellano paraguayo en el coloquio, impregnando a su obra de una vigorosa autenticidad. Con tanta versatilidad como acierto, transita los ambientes populares, sórdidos o de refinado intelectualismo, con una sagacidad cargada de ironía, no excenta de un sarcasmo implacable. Luego de un largo silencio Lucy Mendonça de Spinci, utilizando su nombre de soltera, nos vuelve a enfrentar con las circunstancias más crudas de nuestra ambiente en su último libro Cuentos que no se cuentan (1998), donde intercala relatos breves con meditaciones que denuncian las lacras de la realidad nacional.

Cuando un escritor o escritora emprende la tarea de difundir la literatura de su país en el exterior, con el convencimiento de que esa actitud sirve para romper las barreras del enclaustramiento, se enfrenta con respecto a su propia obra a dos criterios contrapuestos: la inclusión dentro del panorama expuesto o la automarginación. Atendiendo al análisis que vengo haciendo de la escritura como agente de la liberación femenina en la narrativa paraguaya, donde cada autora presenta una arista diferente, opté por el primero.

Renée Ferrer (1944) irrumpe en la narrativa en los años ochenta. Atendiendo a la necesidad de denunciar la realidad por un medio más directo que la poesía, publica La seca y otros cuentos (1986), al cual le sigue La mariposa azul y otros cuentos (1987), dirigido al público infantil, y posteriormente Por el ojo de la cerradura (1993), una serie de cuentos donde se intenta desvelar esa otra realidad que está más allá de la apariencia y sólo puede verse «por el ojo de la cerradura». Convocada por una ONG dedicada a la defensa del medio ambiente, aborda el tema ecológico en el libro Desde el encendido corazón del monte (1994). Su obra novelística se inicia con Los nudos del silencio (1988), donde asume la defensa de la vocación de la mujer y la denuncia del sometimiento al sistema patriarcal en una sociedad autoritaria denigrada por la dictadura de Alfredo Stroessner. Su segunda novela Vagos sin tierra (1998), ubicada en la zona norte del Paraguay del siglo XVIII, narra las desventuras de los campesinos que van a la frontera atraídos por la promesa de los repartimientos de tierra.

Los mecanismos de liberación de la mujer van desde la locura, en La colección de relojes, a la alienación voluntaria en El ovillo, hasta el lesbianismo pasivo asumido por $\mathrm{Mei} \mathrm{Li}$ en Los nudos del silencio. Si Malena, la protagonista burguesa, que renunció a su carrera de pianista por el casamiento, se subleva y toma conciencia de su sumisión al varón frente al streep-teese de Mei-Li, ésta opta por refugiarse en una relación lesbiana como respuesta a la abusiva conducta masculina.

Las voces aparecidas en la narrativa paraguaya en la década de los noventa son en su mayoría femeninas, y el género más frecuentado el cuento breve. Milia Gayoso (1962), de prosa escueta y efectiva, inicia su producción con Ronda en las olas (1990), al cual le siguen
La liberación de la mujer

a través de la escritura

RENÉE FERRER 
Un sueño en la ventana (1991) y El peldaño gris (1994), sustentados en la observación de la vida ciudadana, con sus ribetes de desamparo que se encuentra en las urbes. Por su parte Chiquita Barreto Burgos (1947), por medio de un discurso crítico y directo, suma a la bibliografía nacional dos colecciones de cuentos, donde campea el humor y la denuncia. Con pena y sin gloria (1990) y Con el alma en la piel (1994), de hondo contenido erótico, son algunos títulos de esta autora. Hay que destacar que en una sociedad convencional donde la liberación femenina cuenta con un escenario reducido, la escritura de Barreto Burgos constituye un desafío que afianza la postura de la mujer frente a unos patrones de conducta arcaicos, insuficientes para sojuzgarla. Varias son las escritoras y poetas que ejercen el derecho a la réplica y a la libertad a través del discurso poético o narrativo, pero Chiquita Barreto es la primera que articula una serie de cuentos sobre el eje del erotismo.

Predomina en la narrativa actual paraguaya la ficción breve. En 1992 tres integrantes del Taller Cuento Breve, dirigido por Hugo Rodríguez Alcalá, se dan a conocer. La primera es Luisa Moreno (1949), con Ecos de monte y arena (1992), quien utiliza un discurso impregnado de ternura y precisión semántica para abordar temas ecológicos, denunciando el peligro de la destrucción de la naturaleza y el reino animal. A este primer libro le sigue El último pasajero y otros cuentos (1997), donde la autora hace gala de un estilo preciso y de buena penetración psicológica, mezclando muchas veces los planos de la realidad y la fantasía para llegar a la denuncia o al misterio, que queda flotando en el entorno al lector.

Maybell Lebrón (1923) se da a conocer al poco tiempo con Memoria sin tiempo (1992), donde por medio de una prosa prístina, y muchas veces poética, encuentra el tono dentro de la diversidad temática. En Maybell Lebrón se conjugan la denuncia política como en su cuento «Orden Superior» o la afirmación de la libertad de la mujer, que incluso llega al crimen como afirmación de su libre albedrío.

Completa la tríada de ese año Dirma Pardo Carugati (1934), cuyo estilo preciso, de una marcada impasibilidad, potencializa el dramatismo de sus invenciones, reunidas en su libro de cuentos La víspera y el día (1992).
En 1999, con la publicación de Cuentos de tierra caliente, Dirma Pardo Carugati da nuevamente muestras de su habilidad narrativa, utilizando certeramente el recurso del final inesperado. En Dirma Pardo encontramos un planteamiento diferente con respecto a la liberación a través del discurso. Si Neida de Mendoça propone el suicidio del personaje femenino como un escape a la desesperación, Dirma lo encara como venganza en su cuento titulado precisamente «Venganza», publicado en la revista Manzanas al Olmo.

La producción narrativa de la mujer sigue siendo en el presente un fenómeno ascendente. Desde los textos centrados en la vida cotidiana hasta la fabulación fantástico-metafísica, la mujer sigue su derrotero de contar no solamente su mundo personal y sino también «el mundo» tal cual lo ve desde su óptica femenina y muchas veces feminista.

Yula Riquelme de Molinas (1941-2002) da a conocer la novela Puerta (1994), saliéndose de los cánones habituales de la narrativa femenina para rozar la literatura fantástica, subgénero casi inexplorado dentro de la literatura paraguaya. A esta novela se suma Los gorriones de la siesta (1996), donde mediante una fluida relación de los hechos mantiene interesado al lector, creando una buena dosis de suspenso. Posteriormente publicó De barro somos (1998).

Si en otras narradoras observamos que el proceso de liberación del personaje femenino pasa por la locura, la infidelidad, el lesbianismo e incluso el asesinato, en Los gorriones de la siesta nos encontramos con un personaje delicioso, desprejuiciado y generoso, que ejerce la libertad sexual desde la adolescencia, y lo hace con la alegría de saberse su única dueña, sin dejarse vencer por el peso de los complejos de culpa, tan habituales en los personajes femeninos de la narrativa paraguaya escrita por mujeres. El planteamiento de Yula Riquelme se basa en la resistencia a obedecer y la capacidad de tomar las propias decisiones. La novelística no agota la capacidad narrativa de Yula Riquelme, quien escribe además ficciones breves, como lo atestigua el volumen Bazar de cuentos (1995).

Cierra las publicaciones de 1994 el libro de cuentos El Viaje de Delfina Acosta, quien con una agudeza impregnada de ironía transita el paisaje interior de sus personajes, desenmascarando sus sentimientos y los móviles escon- 
didos de la conducta humana. En su cuento «La tía», Delfina manifiesta claramente el papel de sometimiento de la mujer, pero esta vez la conducta servil se adecua a los deseos despóticos de una tía que se opone sistemáticamente a todos los emprendimientos de la sobrina, incluso el de contraer matrimonio. Delfina resuelve finalmente la situación dictatorial con la huida de la protagonista a la rama de un árbol.

$\mathrm{Al}$ año siguiente se suman a este grupo de narradoras de indiscutible valor Susana $\mathrm{Ri}$ quelme de Bisso con sus cuentos Entre la cumbre y el abismo (1995) y Nila López (1954), quien en su libro Señales (Una intrabistoria) (1995) navega entre la crítica social, el ensayo y el relato certero, y en Madre, bija y espiritu santo (1998) reúne una serie de textos que sin tomar la forma del poema están impregnados de poesía.

En «Despedida al miedo», Nila López nos presenta como solución al problema de la condición de la mujer oprimida por el miedo a ser juzgada y por los complejos de culpa que la sociedad le hace sentir, su propia batalla contra el miedo, de la cual sale finalmente victoriosa. Por su parte, Susy Riquelme de Bisso denuncia la presión social como cerrojo deformante de la conducta de la mujer en su cuento «Anastasia», donde una mujer llega a la muerte a causa de la intransigencia de la sociedad, que le endilga un embarazo causado por el cura párroco, quien a su vez tiene que abandonar el pueblo a pesar de su inocencia por las elucubraciones erróneas y mal intencionadas de la comunidad.

El fenómeno de la proliferación de voces narrativas continúa al filo del fin de siglo. Varias autoras que venían escribiendo desde los años 80 y no habían concretado la publicación de su obra por razones económicas, logran finalmente dar a conocer su producción. Tales son las hermanas Mabel Pedrozo y Amanda Pedrozo quienes publican en conjunto el libro Mujeres al teléfono (1997), donde puede palparse el fuerte cuestionamiento a una sociedad donde la doble moral y la corrupción se han convertido muchas veces en moneda corriente.

La escritora Lita Pérez Cáceres (1940), inédita durante mucho tiempo, publica finalmente María Magdalena María (1997) haciendo un despliegue de humor, a través del cual manifiesta su protesta contra el orden es- tablecido. La rebelión de Pérez Cáceres es abierta y sin tapujos. En el cuento La carne de Carmela nos describe la conducta de una mujer sin prejuicios a la cual la sociedad tiene finalmente que aceptar tal cual es, luego de sus incontables aventuras, un casamiento por conveniencia del cual se evade por medio de una relación adúltera.

Una de las últimas autoras en manifestarse es Margarita Prieto con su libro de cuentos Tiempo de chivatos (1998), de sabor popular y aguda comprensión del alma campesina, a quienes se suman otras con obra individual inédita, nucleadas en su mayoría en el Taller Cuento Breve, y otras voces jóvenes, tal como la de Monserrat Álvarez con dos novelas cortas y varios libros de cuentos.

Así como la situación desventajosa de la mujer frente al autoritarismo de una sociedad castradora que funciona sobre el esquema de la familia patriarcal, y las denuncias contra la opresión en el marco de la dictadura stronista se han convertido en el ingrediente obligado de la liberación de gran parte de la literatura paraguaya escrita por mujeres actualmente, también se debe destacar el interés por la lengua autóctona, el guarani, y el fenómeno del bilingüismo paraguayo, asumido por la mayoría de las escritoras actuales.

El enfoque de las autoras al problema de la lengua sojuzgada, que subyace y se impone al español en el habla de la mayoría de la población paraguaya, es variado y disímil, tal como lo fue hace cuarenta años para los narradores varones.

El código utilizado es el español, pero se nota una ingente penetración del guaraní en el discurso narrativo, ya sea a través de frases enteras introducidas en dicha lengua y explicadas posteriormente en el contexto, como por la incorporación al discurso narrativo de términos y giros sintácticos del guaraní trasladados al castellano; sin olvidar la utilización del jopara, lengua híbrida, mitad español, mitad guaraní, o del castellano paraguayo que se impuso por medio de la oralidad para penetrar posteriormente la escritura. Si bien podría pensarse que este fenómeno tiene relación con la oficialización del guaraní, equiparado actualmente al castellano, me inclino a pensar que obedece más bien a la penetración de las autoras en la idiosincrasia de sus personajes, cuyos esquemas mentales obedecen frecuentemente a los patrones lingüísticos de su len-
La liberación de la mujer a través de la escritura RENÉE FERRER 
gua materna, el guaraní. Cuanto más rural o marginal es un personaje, más se incorpora el habla al discurso narrativo. $\mathrm{Y}$ ese reconocimiento del guaraní como factor determinante de la personalidad ha dado por resultado la utilización de un lenguaje peculiar en consonancia con la procedencia y situación social de los personajes.

Si bien algunas escritoras se inclinaron por los procedimientos de interpolación o explicación de los vocablos dentro del mismo discurso, Margot Ayala de Michelagnoli optó por el registro del habla popular de los barrios marginales de Asunción, utilizado en su novela Ramona Quebranto (1989), donde desde el título podemos detectar la sintaxis guaraní, a pesar de la utilización de los vocablos castellanos. El significado del mismo es, trasladado a la sintaxis castellana, el quebrando de $\mathrm{Ra}$ mona, algo similar a lo que acontece con la estructura del posesivo en inglés.

Luego de este recuento bibliográfico y temático podemos aseverar que la mujer se ha ganado un lugar preponderante en la literatura paraguaya de hoy, y que su rebelión contra el esquema tradicional se manifiesta cada vez con mayor vigor por medio del oficio de escribir, donde el manejo del discurso narrativo, sea metafórico, sarcástico o irreverente, se utiliza como arma y como escudo, como carta de identidad y de reivindicación.

Para cerrar este panorama de la narrativa femenina en el Paraguay es interesante destacar el papel que le cupo a los talleres literarios de Hugo Rodríguez Alcalá, Carlos Villagra Marsal, Ester de Izaguirre, Jacobo Rauskin, Francisco Pérez Maricevich y Osvaldo Gon- zález Real en el descubrimiento de las voces más recientes de la literatura paraguaya.

Ya se ha mencionado la preocupación de las autoras con respecto a nuestras raíces lingüísticas. Si bien es cierto que el bilingüismo hispano-guarani ha condicionado preferentemente el discurso narrativo de nuestros escritores varones, no se puede dejar de señalar la voluntad de incorporación de la lengua soterrada que manifiestan varias de las autoras mencionadas, así como la utilización del castellano paraguayo en el texto narrativo.

Nos complace constatar la abundancia de voces femeninas, muchas de marcado acento feminista, en la actual narrativa paraguaya, como resultado de una valoración de la mujer, que ha tomado conciencia de su derecho a dar testimonio de sí misma, de los otros y de sus circunstancias, desde un ángulo netamente suyo. El potencial existente en la voz de la mujer, que ahora asume su sexo y su género, y concomitantemente se libera, no puede sino enriquecer la literatura de cualquier región de la tierra.

Concluyendo se puede afirmar que, si bien la narrativa paraguaya ha sufrido un retraso inicial, careciendo de esa tradición centenaria que aureola a otras literaturas del continente latinoamericano, el actual caudal de escritores de ambos sexos, el ritmo de creación, la diversidad de temas, la persistencia en el rescate de la lengua autóctona como garantía de identidad cultural, y principalmente la irrupción decidida y fecunda de la mujer, permiten señalar que se está desarrollando en el Paraguay una narrativa medulosa que el tiempo se encargará de valorar. 